\title{
Utilisation of digital central supplier database in enabling electronic procurement in the Limpopo provincial departments
}

\begin{tabular}{|c|c|}
\hline \multicolumn{2}{|c|}{ 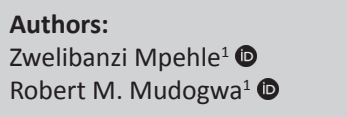 } \\
\hline \multicolumn{2}{|c|}{$\begin{array}{l}\text { Affiliations: } \\
{ }^{1} \text { Department of Public } \\
\text { Management, Faculty of } \\
\text { Humanities, Tshwane } \\
\text { University of Technology, } \\
\text { Pretoria, South Africa }\end{array}$} \\
\hline \multicolumn{2}{|c|}{$\begin{array}{l}\text { Corresponding author: } \\
\text { Zwelibanzi Mpehle, } \\
\text { mpehlez@tut.ac.za }\end{array}$} \\
\hline \multicolumn{2}{|c|}{$\begin{array}{l}\text { Dates: } \\
\text { Received: } 23 \text { Oct. } 2019 \\
\text { Accepted: } 25 \text { June } 2020 \\
\text { Published: } 07 \text { Sept. } 2020\end{array}$} \\
\hline \multicolumn{2}{|c|}{$\begin{array}{l}\text { How to cite this article: } \\
\text { Mpehle, Z. \& Mudogwa, R.M. } \\
\text { 2020, 'Utilisation of digital } \\
\text { central supplier database } \\
\text { in enabling electronic } \\
\text { procurement in the Limpopo } \\
\text { provincial departments', } \\
\text { Africa's Public Service } \\
\text { Delivery and Performance } \\
\text { Review } 8(1), \text { a356. https:// } \\
\text { doi.org/10.4102/apsdpr. } \\
\text { v8i1.356 }\end{array}$} \\
\hline \multicolumn{2}{|c|}{$\begin{array}{l}\text { Copyright: } \\
\text { (c) 2020. The Authors. } \\
\text { Licensee: AOSIS. This } \\
\text { work is licensed under } \\
\text { the Creative Commons } \\
\text { Attribution License. }\end{array}$} \\
\hline \multicolumn{2}{|l|}{ Read online: } \\
\hline 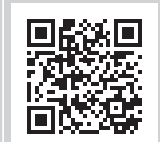 & $\begin{array}{l}\text { Scan this QR } \\
\text { code with your } \\
\text { smart phone or } \\
\text { mobile device } \\
\text { to read online. }\end{array}$ \\
\hline
\end{tabular}

Background: The establishment of a digital central supplier database (CSD) in the Limpopo provincial departments was envisaged not only to eliminate the duplication of service provider compliance requirements during procurement processes and payment processing but also to level the playing field amongst service providers so that small and upcoming businesses can have equal competitive bidding opportunities like any other business. This therefore meant that the CSD was to ensure that all registered suppliers have an equal and fair prospect of providing goods and services to government, and that acquiring of goods and services is done in a cost-effective manner. However, the Limpopo provincial departments are persistently underspending their allocated budgets at the end of each financial year.

Aim: The aim of this study was to assess whether CSD as an electronic procurement (e-procurement) system adopted by the provincial departments in Limpopo is efficient and cost-effective in enhancing the provisioning of goods and services.

Setting: The study focused on the Limpopo provincial departments, South Africa.

Methods: The study used a qualitative research approach to assess the use of CSD in enabling e-procurement processes. Purposive sampling was employed to sample 14 participants from 12 provincial departments.

Results: The outcome revealed that the technological innovation of centralising the suppliers' records on the CSD increased transparency and accountability in the process of selecting suppliers who qualify to do business with government, and the system has the potential, if rightly used, to eliminate corrupt activities such as favouritism and collusion.

Conclusion: The article concludes that the successful implementation of CSD by provincial departments and public entities may, amongst other things, improve supply chain management performance, particularly in the selection of suppliers, and may also promote economic development of small, medium and micro-enterprises.

Keywords: e-procurement; central supplier database; supply chain management; costeffectiveness; economic development.

\section{Introduction}

A digital central supplier database (CSD) as part of an electronic procurement (e-procurement) system is widely perceived by both public and private sector organisations as a system that is necessary for revolutionising the procurement function (Ilhan \& Rahim 2013). According to Anthony (2018), CSD, with its distinct advantages, has been introduced and implemented in various countries for a number of years. Despite some challenges faced by organisations in the implementation of CSD, there have been observable major benefits that are directly linked to the success of organisations, such as an increase in competitive bidding. Competitive bidding often yields the best value for money, as bidders compete fairly in the selling of goods and services, and an organisation has the option to weigh each bid and accept the one that suits it an acceptable value. Bailey and Chen (2018) identify this type of bidding as an 'electronic reverse auction', wherein a single 'buyer' (an organisation) electronically invites 'sellers' (bidders) as prospective suppliers to bid and finally chooses a bidder that meets the requirements. The process requires the active involvement of prospective suppliers during the bidding and awarding of a tender. It would be a misnomer therefore to mention CSD without twinning it with e-procurement, as the former is part of the latter. 
For any government to improve the economic development of its citizens and the country's economic growth, it needs a good CSD and procurement systems that will enable it to acquire goods and services in an effective and efficient manner However, generally in African countries the digitisation of procurement processes has not been extensively developed as a result of the governments in these countries being slow to put in place the required human resources, the unavailability of necessary information technology infrastructure and the widespread lack of Internet access (Anthony 2018).

The South African government has made some strides in improving the above-mentioned enablers of smooth e-procurement. As stated by Section 217 of the Constitution of the Republic of South Africa, 1996 (hereafter referred to as 'the Constitution'), there is a standard set by government when it comes to procurement of services and goods. The set standards state that the national, provincial and local spheres of government and any other relevant institution identified in the national legislation have to procure goods and services in a 'fair, equitable, transparent, competitive and cost-effective' manner (Anthony 2018). Although the Constitution does not define fairness, equity, transparency, competitiveness and cost-effectiveness, the International Comparative Legal Guides (2019) mentions that South African courts have provided clarity on what these terms mean. 'Fairness' and 'equity' refer to dissemination of information to all bidders in a non-discriminatory manner and the adjudication of bids being done without bias. 'Transparency' then would mean that the procurement process must promote openness, ensuring that reasons are provided as to why a tender was awarded to a certain bidder over the other, and officials need to account for their actions of awarding the tenders. 'Competitiveness' and 'cost-effectiveness' imply that the procurement process needs to achieve value for money.

Considering global transformation as far as procurement is concerned and the standards set by the Constitution, and for the Limpopo provincial government to measure up to international standards in procuring goods and services in an efficient and effective manner, it was inevitable that the procurement system would be transformed from a manual to an electronic one. However, the Limpopo provincial government is no exception to the challenges facing other African governments, and therefore there is a need for such a study that will look at the challenges that beset the province in the implementation of e-procurement.

This article starts by providing an introduction to the study and defines the e-procurement concept. Furthermore, the advantages and enablers of e-procurement are discussed. Additionally, the article deliberates on e-procurement in South Africa and the legislative framework that guides such a process. The research aims and objectives are discussed, and finally the findings and recommendations are provided.

\section{The concepts of the central supplier database and e-procurement}

The CSD is a single database of prospective and qualified service providers of the state and serves as 'the source of all supplier information for all spheres of government' (StatsSA 2017). The purpose of CSD is to ensure that e-procurement is enabled by reducing unnecessary 'duplication of effort and cost for both supplier and government' and to open economic opportunities for emerging businesses to do business with government in order to develop a country's economy (More 2016).

Electronic procurement, also known as e-procurement, is the automated procurement of goods and services by an organisation by means of web-based applications, and it should become the most important system of an organisation in the technological era (Anthony 2018). This e-procurement system is increasingly recognised as a system that is potentially transforming the competitive performance of organisations for the better (Corina 2019). According to Van Weele (2010), e-procurement is a technologically web-based system that simplifies business transactions between organisations and is a solution to purchasing, payments, ordering and handling systems.

E-procurement has made substantial technological advantages over the past few years and is expected to continue improving efficiency and productivity in the future. This system has been used by both public and private sector institutions in various countries and in diverse ways as means of creating a competitive, fair and transparent bidding environment for acquiring goods and services from service providers. E-procurement is a system that is perceived to provide good value for money. As such, the system assists in easing an organisation's regulatory processes and also eliminates the unnecessary red tape (Mohd Nawi et al. 2016).

\section{Advantages and disadvantages of e-procurement}

Organisations that have effectively implemented e-procurement of goods attest that it is the most cost-effective way of acquiring goods, as it ensures that goods are obtained at a lower price, thereby reducing administrative costs and that of the goods, promoting efficiency as far as operations are concerned and reducing corruption and turnaround time. E-procurement also reduces the time of transfer of money between computer-generated accounts, and therefore the time of delivery becomes shortened and costs are significantly reduced. An automated transaction process speeds up the completion of buying of goods and services (Nawi et al. 2017). The following are the advantages of having a good e-procurement system.

\section{Accessing of global markets}

E-procurement opens doors for the international acquisition of goods and services. It therefore becomes imperative for 
organisations to have e-procurement applications that will increase worldwide accessibility of goods and services rather than depending on local products that quite often are not available, and if available are expensive (European Bank for Reconstruction and Development 2015). Nevertheless, governments in developing markets are often not aware of the benefits of e-procurement, as some governments in developing countries are reluctant to adopt e-procurement because they do not want full transparency in the procurement system for reasons related to corruption and other dishonest transactions (Purchasing \& Procurement Center 2017). As much as digital procurement can be 'an important economic value-add' for small or emerging businesses as it can act as a catalyst for 'faster procure-to-

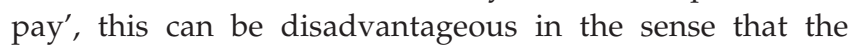
growth of local business can be stifled by fierce international competition (Hadden 2016).

Certain basic requirements need to be fulfilled before an e-procurement system can achieve its maximum potential in government. These are recommendations made by the World Bank, which include expanding the information and communications technology (ICT) services, guaranteeing a secure online environment, developing standards and processes and, most importantly, training purchasers. Although accessing of global markets can serve as an advantage, it can also be a disadvantage in that small businesses can be destroyed.

\section{Cataloguing electronically}

In the process of e-procurement, e-cataloguing usually becomes a necessity, and if rightly employed, it can be an effective tool for suppliers to electronically market their products, which can serve as an advantage in that the buyer can easily compare prices from different suppliers (Anthony 2018; Ilhan \& Rahim 2013). Electronic cataloguing makes it easier for an organisation to regularly update information at a minimal cost for suppliers to easily access the necessary information in order to know what an organisation needs at a particular time. Electronic cataloguing ensures accuracy of information to a wide clientele base. This type of cataloguing also assists in increasing the competitive edge of an organisation (Intertrade 2019).

\section{Flow of information}

An e-procurement process simplifies the flow of information between an organisation and bidders and between the organisation and the recipients of the services. Given the fact that bidders are to a greater extent actively involved in the actual procurement process and are always informed of the bids of competitors and their prospective success in the bidding process, e-procurement promotes transparency between an organisation and the bidders, and that transparency has a propensity to curb corruption (Anthony 2018; Mohd Nawi et al. 2016). However, taking into consideration the fact that the introduction of e-procurement may necessitate the acquisition and utilisation of new software tools, there will always be challenges and disadvantages in the implementation process. Below are the disadvantages that an organisation may come across.

\section{Lack of infrastructure and legislation}

For e-procurement to be effective there needs to be a good infrastructure, as the lack of it will serve as a barrier to effective implementation. Supporting infrastructure such as broadband coverage and the availability of physical resources such as appropriate buildings and equipment are key to the proper functionality and use of an e-procurement system. Moreover, governments are generally known to have inadequate policies and legislation to address the challenges that come with the digitisation of procurement, and in many cases this causes a large setback for the establishment of an electronic government system (Husain \& Mustaffa 2012).

\section{Culture shock}

The introduction of new software may create an unexpected culture shock precisely because digital transformation may not necessarily be an easy thing to adapt to by employees who are supposed to acquaint themselves with and use the new software. Some may perceive it as a threat to their jobs and therefore may be reluctant to abandon the traditional way of doing things (PurchaseControl 2019).

\section{Situation-specific integration issues}

If an organisation does not adequately plan for the introduction of the new system, or employees lack a thorough understanding of the reasons as to why a new system is necessary, there is bound to be conflict that may lead to the failure of the implementation of the new system. Proper planning includes analysing the capabilities and operational level of the new e-procurement system and determining whether it will serve the purpose it was procured for (PurchaseControl 2019).

\section{Enablers of e-procurement}

When deciding to introduce e-procurement, it is imperative for any organisation to reasonably assess its readiness to implement such a system. Readiness in this instance refers to the availability of good infrastructure, adequate training provided to staff members and all stakeholders who may benefit from the system, and the formation of partnerships. Furthermore, as stated by Ilhan and Rahim (2013), there needs to be commitment by senior management towards implementation of the system and willingness to share necessary information and knowledge with suppliers. Figure 1 illustrates the enablers in diagrammatic form.

\section{Willingness of senior management to introduce e-procurement}

Prior to the introduction of any technology-driven programme in an organisation, it is of utmost importance that managers survey the needs of employees as far as 


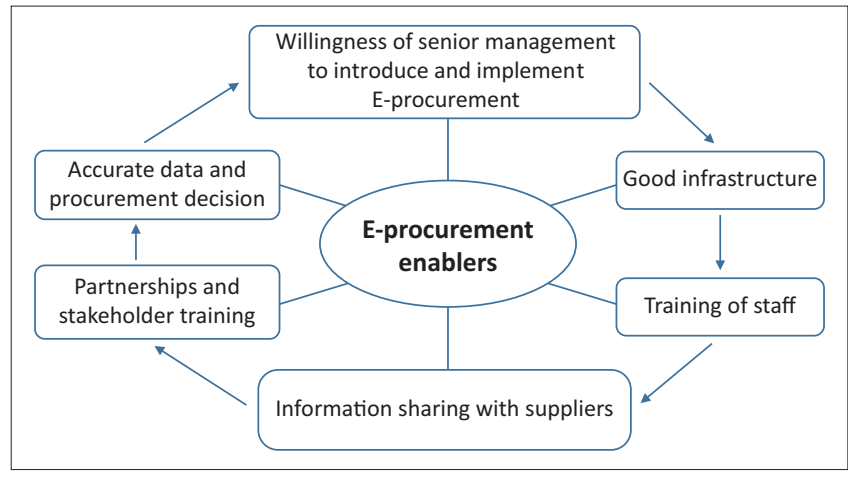

E-procurement, electronic procurement.

FIGURE 1: The e-procurement enablers.

technological advancement is concerned. This will assist in providing the necessary and appropriate training in order to improve customer service. Principally, senior management is responsible for steering an organisation in a direction that will see it strategically succeeding in improving the efficiency of operations. When employees are properly trained, their performance will significantly improve, which in turn will assist in ensuring that the organisation tracks its spending and how money is expended. Investing in the training of employees boosts their morale and motivation precisely because they perceive that they are valued and appreciated. Proper training of employees will also assist in '... reducing material costs, consolidating procurement demands, facilitating faster procurement cycles, rationalising their supplier base, and identifying new procurement opportunities' (Hsiao \& Teo 2005:1).

\section{Good infrastructure}

Although training of stakeholders is necessary, the top management needs to ensure that the training is complemented by the appropriate infrastructure (Anthony 2018). While establishing an infrastructure, it should be in mind that the infrastructure specifically addresses the existing business challenge. In other words, the relevant infrastructure becomes key in enabling 'proper document management' and also 'keep[ing] track of the standards needed in contracts to ensure consistency' (Gulwa 2017). This therefore means that the technology introduced should promote communication that is open between government agencies and bidders so as to minimise the confusion and misunderstanding that may arise during the tender process, as that may derail the delivery of services to citizens.

\section{Providing training for staff}

One of the many challenges faced by organisations in implementing an effective e-procurement system is user adoption that is negatively affected by staff members who are not well trained in the use of such a system. As stated by Anthony (2018), a successful implementation of an e-procurement system depends on the knowledge of the staff members and the support given to them by an organisation. Wins (2017), in support of this view, states that for any organisation to effectively implement e-procurement that will lead to high productivity and profitability, there need to be properly trained and informed staff through providing, inter alia, scenario-based e-learning courses where employees learn through real-life situations that they relate to and therefore provide amply pertinent learning experience. Scenario-based learning and other types of training allow staff members to experience real work situations and be more engaged so as to apply the skills and knowledge gained to their jobs. This therefore implies that staff members need to know what exactly the e-procurement concept entails, as this will ensure alignment of what they do with the organisation's objectives. If employees are provided with proper training, they can deal with the automated matching of invoices; goods can be ordered, processed and paid for within minutes. Through such practices, staff can work in a more strategic way to meet the objectives, thereby increasing the productivity rate.

\section{Partnerships and training of stakeholders}

In order for a government to be successful in e-procurement, it has to consider a long-term partnership with the private sector and learn from the advancement and best practices of the sector in electronic bid management. It therefore becomes important that the private sector is committed to assist government because without its commitment, the government's e-procurement may fail. Therefore, it is essential that both sectors (public and private) work together so as to share information and understand the global changes taking place in order to adapt (Gulwa 2017).

Again, for e-procurement to yield the desired procurement results in an organisation, it is imperative for all stakeholders, particularly suppliers, to be extensively trained in the use of web-based procurement. Hence, developing a positive attitude towards the use of technology is paramount (Anthony 2018). More importantly, staff members need to be educated as far as technology goes in order for e-procurement to succeed. As stated by Gulwa (2017:1), 'skilled procurement personnel are crucial to a well-functioning e-procurement system, requiring government to recruit skilled procurement staff and continually train them (classroom training, on-thejob training and mentorship)'.

\section{Sharing information and knowledge with suppliers}

In order for any organisation to have a competitive advantage, it is important to ensure that information and knowledge are adequately shared with every stakeholder. In the case where an organisation needs to introduce and implement e-procurement, both internal customers and suppliers need to be well informed about the developments because disseminating necessary information is one of the pillars of a successful e-procurement system. If information is not fully shared, suppliers will not be able to access the most important data, therefore negatively affecting proper procurement planning, making it difficult to effectively make decisions 
related to procurement, and this will hamper suppliers' preparation to deliver the necessary goods and services (Ilhan \& Rahim 2013).

\section{Accurate data for good decision-making}

According to Hamzah et al. (2018), data capturing is a method used to put information either from a document or any other source into an electric format, and it has become an important part of successful organisations. Capturing and keeping accurate procurement data is a major component of an e-procurement system because it determines the success of an organisation. Data that are accurately captured can be of good assistance to the planning of senior management in order to determine and achieve organisational strategic goals. Accurate data are utilised to provide an organisation with meaningful insights so as to enable senior management to improve the day-to-day decision-making. Therefore, accurate and efficient data capturing is of utmost importance (Cotton 2014; Cross 2017).

\section{E-procurement in South Africa}

African countries are generally not as advanced as developing countries as far as the adoption and use of e-procurement is concerned, and the reasons behind this slow progress include slowness in ensuring the establishment of basic and adequate capacity, inadequate information and technology infrastructure, inability of these countries to provide mass Internet access and a fixed administrative culture that does not easily adapt to global technological advancement (Anthony 2018; Thomas et al. 2007). As much as global governments in the last two decades have pursued modernisation of procurement systems, some still face challenges in the implementation of e-procurement, and South Africa is no exception. It is noteworthy that the introduction of e-procurement in the South African government was to ensure that there is good governance and good spending of limited public funds. The government aimed at delivering goods and services in the most efficient manner and strives to save as much public funds as possible in order to avail more resources to citizens (Gulwa 2017).

As a developmental state, the South African government has to ensure that all suppliers, especially the previously disadvantaged class of people, do business with government in an accessible manner, and digitisation of the procurement system will make it easy for even small businesses to access economic opportunities. An e-procurement system that is open and accessible offers clear procurement guidelines and facilitates the easy submission of documents, whilst at the same time minimising a cumbersome handling of documents (hard copies) and the duplication thereof, and in turn assists in the empowering of small businesses. It was important for the South African government to introduce e-procurement because the old traditional system was plagued by a lack of accountability, and therefore e-procurement was envisaged to promote transparency and faster turnaround time (Gulwa 2017).

\section{Legislation on e-procurement in South Africa}

Although there is no legislation that specifically addresses the subject of e-procurement, there is reference to the procurement of goods and services by government in a 'fair, equitable, transparent, competitive and cost-effective' manner, as captured in Section 217 of the Constitution . This therefore implies that the processes and procedures in contracting goods and services should be accessible and transparent to potential suppliers, and that equal opportunity in the evaluation of bids and awarding of contracts to bidders should be a norm. This means that contractors are evaluated against the backdrop of Section 9 of the Constitution. In order to give effect to this section and the equality element in Section 217 of the Constitution, contractors' socio-economic circumstances are considered when evaluating their bids. Contractors may therefore be treated differently in view of South Africa's past discriminatory practices (Anthony 2018). In practising equality in the entire procurement process, the socio-economic conditions of previously marginalised individuals need to be taken into consideration as stated in Section 9 of the Constitution. More importantly, government needs to ensure that the process saves time and is costeffective. This means that administrative costs need to be minimised, indirectly advocating for less paper usage and more use of e-procurement.

The Electronic Communications and Transactions Act 25 of 2002 (ECTA) has provisions for government to conduct its business electronically with small, medium and micro-enterprises (SMMEs), and sections 27 and 28 encourage the use of e-governance services to, amongst other things, develop human resources and electronically transact with other entities that do business with government. Section 6(a) further provides that the government should have an e-strategy that indicates the nature of Internet programs that will 'expose' disadvantaged communities to Internet usage (Anthony 2018). It therefore implies that the ECTA advocates for e-procurement.

One legislation that mentions e-procurement is the Preferential Procurement Policy Framework Act (PPPFA) with its regulations addressing preferential procurement and how policies that have to do with procurement need to be implemented. This piece of legislation, together with the Public Finance Management Act no. 1 of 1999 (PFMA) at the national and provincial levels, and Local Government: Municipal Finance Management Act no. 56 of 2003 (MFMA) at the local government level, emphasises the prudent use of public funds, therefore generally implying cost-saving processes to be implemented in all spheres of government (Anthony 2018).

\section{Aim of the study}

The aim of this study was to evaluate the effectiveness of CSD as an e-procurement system adopted by the provincial departments in Limpopo province to increase transparency and accountability in the process of managing and selecting suppliers who qualify to do business with government in 
order to obtain the best value for money. The objectives are as follows:

- to establish the effect of e-procurement in expediting the acquisition of goods and services by provincial departments

- to assess the reliability of online databases for suppliers in managing and selecting suppliers who qualify to do business with provincial departments

- to determine the effectiveness of government procurement digitisation in making procurement of goods and services more efficient and cost-effective

- to ascertain if the provincial departments' employees possess the required skills to deal with e-procurement for provision of quality service.

\section{Research methods and design}

As the study explored the use of an e-procurement system in Limpopo provincial departments to determine its effectiveness, and to have a better understanding of the existing challenges in the use of digital procurement, a qualitative approach was used. The researchers preferred an exploratory approach so as to be familiar with the current e-procurement phenomenon and to acquire new knowledge into the phenomenon, because they believed that the phenomenon had elements that required enquiry or warranted discovery. The researchers approached the research with flexibility and open-mindedness (Stebbins 2011). Because a qualitative approach was used, primary data were collected through interviews using a semi-structured interview schedule with 14 participants. These were purposively sampled, as they were envisaged to provide relevant information because they are directly involved in the implementation of e-procurement. Secondary data were gathered from, inter alia, academic journal articles, books, reports, the Internet and government documents.

\section{Findings}

The findings of the study are presented next.

\section{Dependability of the central supplier database in managing and selecting suppliers}

The development and implementation of a technological government procurement system that provides a suitable and reliable platform for procurement is essential. Nine (64\%) of the participants expressed that the CSD initiative was a reliable tool for managing and selecting suppliers who qualify to do business with government in order to obtain the best value for money. According to these participants, the CSD gives departments the opportunity to access service providers from various areas (provinces and regions), and that in itself provides an opportunity to assess whether the prices of the required products were market related.

Five $(36 \%)$ of the participants indicated that the CSD was not reliable because the suppliers are not vetted when registering, and most of the suppliers register for a commodity that they do not specialise in in terms of their business operations, for example, suppliers who are not in the transport industry are permitted to register on transport services.

\section{Digitisation of government procurement}

Nine participants (64\%) expressed that digitisation of government procurement makes the acquisition of goods and services by provincial departments more efficient and cost-effective. These participants stated that the standardised and electronic verification of supplier information leads to less use of paper copies and manual processes. The participants further indicated that service providers are required to have an email address in order to create a user account on the CSD. This helps the departments to electronically send requests for quotations, and service providers are then able to submit their quotations electronically to the concerned department. Five participants $(35 \%)$ mentioned that digitisation of government procurement is not fully implemented in some departments because of lack of information technology infrastructure, such as computer, networking and other components such as software.

\section{Required skills to use procurement technologies}

Ten participants $(71 \%)$ cited that the majority of procurement practitioners in government possess the required skills to deal with procurement technology. One of the participants highlighted that:

'Most of the procurement practitioners in government are state accountants who possess BCom degrees from higher institutions of learning'. (Participant A, Senior Internal Auditor, 28 Feb. 2019).

Four of the participants (29\%) noted that some of the departmental staff do not have proper qualifications for the procurement service they are rendering. Therefore, further education is required to equip them to deal with complex government procurement technologies.

\section{Training provided to officials}

Training plays an important role in enabling supply chain practitioners and service providers to use the electronic government procurement system. All 14 participants (100\%) stated that the provincial treasury provided training to provincial departments' supply chain practitioners and service providers preceding the implementation of the CSD, and the CSD call centres were established in all the districts to address the rising operational challenges. One of the participants indicated that:

'Treasury has provided training to all staff in finance and supply chain management prior [to] the implementation and CSD roll out campaign was conducted to ensure that government staff and service providers are conversant with the system'. (Participant B, Deputy Director: Financial Management, 26 Feb. 2019).

In terms of the usefulness of the technological training provided by the Limpopo Provincial Treasury, 12 participants 
(approximately 86\%) indicated that the training was very useful because the users were able to use the system and assist their respective departments and service providers. However, two participants (14\%) believed that the provided training was not as comprehensive as it was supposed to be because of the marginal training period of a 1 week.

\section{Implementation of technological procurement}

According to 13 of the participants (93\%), the implementation of the technological procurement method is a perfect solution to the problems associated with the traditional methods of procurement by provincial departments. A participant further indicated that technological procurement is transparent, justified, reasonable and proportionate, and fewer problems are encountered because automatic online supplier selection is used. The benefit of implementing technological procurement is that electronic documents and communications between government employees and service providers are traceable. Only one participant $(7 \%)$ revealed that service providers have no confidence in the protection of confidential information required by the CSD, which is mandatory for registration.

According to 11 participants (79\%), the functioning and implementation of e-procurement in the province is helping the provincial departments to minimise procurement corruption and strengthen the supply chain management (SCM) practice's control. One of the participants indicated that:

'As much as corruption can never be eradicated, this e-procurement has minimised and strengthened the SCM control measures. The processes are more transparent'. (Participant C, Deputy Director: Financial Management, 27 Feb. 2019).

Three of the participants (21\%) indicated that e-procurement was not contributing to corruption reduction or improving the inefficiency of public procurement systems. According to these participants, the implementation of e-procurement was not eliminating corruption or assisting the departments to cut the wastage of public funds when the government is engaged in the activity of buying goods and services from suppliers. One of the participants stated that:

'The inability for the system to rotate service providers makes it difficult to assess if procurement corruption is minimized'. (Participant D, Procurement Officer, 24 Feb. 2019).

\section{Accurate information retrieval and better procurement decisions}

An important aspect of supply chain management is demand management, particularly the selection of suppliers for better procurement decisions and achievement of value for money. Eight participants $(57 \%)$ stated that demand management units in the provincial departments were able to make accurate decisions because the CSD is linked with other institutions, such as banks, South African Revenue Services (SARS) and the Companies and Intellectual Property Commission (CIPC), to avoid doing business with tender defaulters or restricted suppliers.
Six participants (43\%) stated that rotation of suppliers when inviting quotations through the CSD was a challenge as the system does not provide a rotation function. This technological obstacle poses the risk of the supplier overriding the system in choosing service providers to do business with government. This practice is hindering the effectiveness of the e-procurement system implementation.

\section{Challenges associated with the technological government procurement method}

The participants highlighted the following challenges that are associated with the technological government procurement method:

- The CSD does not use a rotation method in selecting suppliers who qualify to do business with the department, and manual intervention is used.

- The CSD permits service providers to register in various industry classifications as well as the goods and services they supply per location without capacity validation.

- There is a lack of information technology infrastructure such as mass Internet access.

- The CSD allows the service providers to register using different physical addresses, and as a result, service providers from far away are considered for local procurement opportunities and fail to deliver because of a tight lead time or delivery costs.

- The CSD functional performance is limited to a database, not the entire procurement process.

\section{Analysis of findings}

The following are the findings of the study.

\section{Dependability of the central supplier database in managing and selecting suppliers}

A better way to select suppliers is by looking not only at the current quality but also at their quality record and their potential for further improvement (Goffin, Szwejczewski \& New 1997). The e-procurement process has a positive effect on good governance practice, increasing cost-effectiveness and accountability and decreasing collusion amongst vendors. E-procurement needs to be given the highest priority in terms of implementation to promote a sound public procurement system.

\section{Digitisation of government procurement}

The digitisation of government procurement requires technical skill on the part of users, especially in relation to the use of computers (Mpinganjira 2012). E-procurement uses the Internet to process the transactions and reduce procurement time, and it uses electronic verification of supplier information, which leads to less use of paper copies and manual processes.

\section{Skills required to deal with e-procurement for provision of quality service}

Non-compliance with the procurement processes and procedure is triggered by the lack of requisite skills, capacity 
and knowledge of the employees to fully implement procurement function. According to Zitha, Sebola and Mamabolo (2016), compliance with the procurement processes requires a certain knowledge base with regard to the procurement processes. Public officials need to have skills and knowledge of how to undertake the process of supply chain management in a fair and transparent manner, because if they are not skilled, they may end up awarding tenders to unqualified service providers, which in turn will lead to poor service delivery.

\section{Training of employees}

According to Tshamaano (2012), the chief financial officer (CFO) is responsible for training and developing managers and supervisors to operate and manage a variety of activities within the SCM unit. The procurement staff members of the provincial departments need to be trained in order to learn the specific knowledge or skills needed to improve their performance in their current roles. Further in-depth training on technological procurement will allow provincial department staff to strengthen their skills.

\section{Implementation of technological procurement}

Implementation of the Internet-based system is important for business process re-engineering of the procurement activities (Mahmood 2013). The implementation of e-procurement is potentially beneficial because it ensures efficient public procurement processes that result in reduced costs and time periods (Anthony 2018).

\section{Effectiveness of e-procurement in minimising procurement corruption and strengthening the control of supply chain management practices}

Information technology has changed how goods and services are purchased in the public sector (Rotchanakitumnuai 2013). The government uses the Internet to deliver services and to communicate with provincial department officials and service providers. Whilst corruption exists in all areas of government activity, it is in the area of procurement activity that it is most rampant (Raymond 2008). An e-procurement system is a major breakthrough in the government bidding system, freeing the process from corruption and hassles (Daily Star 2011e). The inevitable decrease in human intervention in the e-procurement process will curb corruption and ensure that bidders are treated fairly (Anthony 2018).

\section{Accurate information retrieval and better procurement decisions}

It became evident from the study that the provincial government does all it can to fight corruption. However, the non-rotation of suppliers makes government procurement inefficient and not cost-effective precisely because departments request quotations from service providers in an anomalous and delinquent manner. Croom (2000) states that the efficiency of the process is important in driving e-procurement performance. To ensure uniformity in applying a CSD system, proper records of rotation of suppliers must be kept by the institutions for audit purposes.

\section{Recommendations}

Although the introduction of an e-procurement system in South African public institutions is to be applauded, on a limited scale, there are hindrances that need to be solved, as mentioned in the findings. Therefore, the government has to reform the entire procurement process to enhance governance standards through information technology utilisation. The following are the recommendations:

- The lack of aptly skilled personnel or staff members has to be promptly addressed as it affects the effective implementation of e-procurement. The government should expedite its efforts to maintain information technology infrastructure. The Internet service infrastructure should be updated across Limpopo province in order to meet the CSD requirements.

- The provincial treasury needs to ensure that workshops across the provincial departments are arranged for procurement practitioners and all other interested stakeholders to make certain that extensive and appropriate training is provided to increase the efficiency of the e-procurement system. Again, it is important that the government adopts an approach that promotes the rotation of suppliers because the system does not have this function at the moment.

- The CSD should also have a limit in terms of the number of commodities that each company can register. This will enable the emerging small and medium enterprises to focus on their core business activities.

\section{Conclusion}

The introduction of CSD represents a massive step towards the digitisation of government procurement in order to reduce procurement wastage and corruption. The implementation of CSD, if properly administered, can be beneficial for the Limpopo provincial departments by providing them with accurate service provider information in a transparent manner. This may dramatically improve the departments' spending. A successfully implemented and sustainable e-procurement system can positively contribute to the healthier performance of a public institution, and that may have a ripple effect on a country's economy. The introduction of e-procurement by the South African government promises to be a step forward in the acquiring of goods and services by creating a platform where value for money, because of possible reduced costs, would be promoted. The notable advantages of e-procurement are the fair competitive bidding in which bidders are actively involved in the bidding and award process, the shorter turnaround time in the delivery of goods and services, fewer staff and therefore reduction of bureaucracy, and promotion of transparency. For e-procurement to be successful and sustainable, there needs to be training of staff members and other stakeholders on how to effectively utilise the 
procurement system, a good infrastructure and a framework of good procurement legislation. It is therefore undeniable that the lack of supporting infrastructure and progressive procurement legislation can impede the successful implementation of e-procurement. Other factors that can hinder the success of an e-procurement system include culture shock, lack of planning, inability to retrieve accurate information and poor procurement decisions.

\section{Acknowledgements}

The authors would like to thank the following people for their assistance during the course of this study: Mashimbye Minah Sindisa, Shingange Mokgadi, Maja Iris Ramadimetja, Mathakho Nditsheni Norman, Mochena Victor, Thando Ntshumeni, Nkhumeleni Shonisani who are responsible for management of procurement and invoices payment for their respective departments; Zitha Hasani and Muthivhi Mbengeni who deal with demand management and supply chain management advice to provincial departments; Seopa Alfred who manages the procurement of Polokwane Welfare Complex and Ramatjie Julius who manages the Supply Chain Limpopo Gateway Airport Authority; Siavha Fhatuwani and Oosthuizen Anelda who perform all procurement-related duties, including ordering, inviting quotations, buying and storing; Nembudani Vhutshilo, Zitha Hasani and Ramatjie Julius who undertake the procurement inspection and ensure that expenditure on goods and services procured is aligned with the approved budget.

\section{Competing interests}

The authors declare that no competing interests exist.

\section{Authors' contributions}

All authors contributed equally to this work.

\section{Ethical consideration}

This article followed all ethical standards for carrying out a research without direct contact with human or animal subjects.

\section{Funding information}

This research received no specific grant from any funding agency in the public, commercial or not-for-profit sectors.

\section{Data availability statement}

The data that support the findings of this study are available from the corresponding author, Z.M., upon reasonable request, who would provide due reference.

\section{Disclaimer}

The views and opinions expressed in this article are those of the authors and do not necessarily reflect the official policy or position of any affiliated agency of the authors.

\section{References}

Anthony, A., 2018, 'The use of e-procurement in South African public procurement law: Challenges and prospects', Law Democracy \& Development 22(1), 39-47.

Bailey, M. \& Chen, C., 2018, 'Introduction to reverse auctions: The BucknellAuto game', INFORMS Transactions on Education 18(2), 116-126. https://doi. org/10.1287/ited.2017.0180

Corina, P.S., 2019, The role of e-procurement in the purchasing process, viewed 15 April 2019, from https://www.researchgate.net/publication/227462923_THE ROLE_OF_THE_E-PROCUREMENT_IN_THE_PURCHASING_PROCESS

Cotton, J., 2014, Data: The importance of accuracy, integrity and real-time integration, viewed 03 July 2019, from https://www.informationbuilders.com/blog/jamescotton/19152.

Croom, S., 2000, 'The impact of web-based procurement on the management of operating resources supply', Journal of Supply Chain Management 36(1), 4-13. https://doi.org/10.1111/j.1745-493X.2000.tb00065.x

Cross, M., 2017, The importance of accuracy in data entry, viewed 03 July 2019, from https://bizfluent.com/info-8035439-importance-accuracy-data-entry.html.

Daily Star, 2011, 'Government approves guidelines for e-procurement (2011e)', Daily Star, 25 January 2011, viewed 11 January 2019, from https://www.thedailystar. net/news-detail-171394.

European Bank for Reconstruction and Development, 2015, Are you ready for eProcurement? Guide to electronic procurement reform, European Bank for Reconstruction and Development, London.

Goffin, K., Szwejczewski, M. \& New, C., 1997, 'Managing suppliers: When fewer can mean more', International Journal of Physical Distribution \& Logistics Management 27(7), 422-436. https://doi.org/10.1108/09600039710188486

Gulwa, P., 2017, E-procurement an international perspective, viewed 19 March 2019, from https://www.smartprocurement.co.za/review/2017/02/e-procurement-aninternationalrocurement-an-international-perspective.html.

Hadden, D., 2016, Benefits of E-procurement in government, viewed 16 January 2020, from https://freebalance.com/public-financial-management/benefits-of-eprocurement-in-government/.

Hamzah, A.A., Yatin, S.F.M., Ismail, N.A. \& Ghazali, S.F., 2018, 'Data capturing: Methods, issues and concern', International Journal of Academic Research in Business and Social Sciences 8(9), 617-629. https://doi.org/10.6007/IJARBSS/v8-i9/4642

Hsiao, R. \& Teo, T.S.H., 2005, 'Delivering on the promise of e-procurement', MIS Quarterly Executive 4(3), 343-360.

Husain, W. \& Mustaffa, N., 2012, 'Survey on benefits and barriers of e-procurement: Malaysian SMEs perspective', International Journal on Advanced Science Engineering Information Technology 2(6), 14-19. https://doi.org/10.18517/ijaseit.2.6.238

Ilhan, N. \& Rahim, M.M., 2013, 'Understanding e-procurement systems benefits: A theoretical model with initial findings from an Australian Local Council', Proceedings of the 24th Australasian Conference on Information Systems (ACIS2013), Melbourne, December 4-6, 2013, RMIT, Melbourne.

International Comparative Legal Guides, 2019, South Africa: Public procurement 2019 viewed 16 December 2019, from https://iclg.com/practice-areas/publicprocurement-laws-and-regulations/south-africa.

Intertrade, 2019, How can an electronic catalogue help your sales? viewed 27 November 2019, from https://www.intertrade.com/edi-resources/supplychain-insights/how-can-an-electronic-catalogue-help-your-sales.jsp.

Mahmood, S.A.I., 2013, 'Public procurement system and e-Government implementation in Bangladesh: The role of public administration', Journal of Public Administration and Policy Research 5(5), 117-123. https://doi.org/10.5897/ JPAPR11.070

Mohd Nawi, M.S., Roslan, S., Salleh, N.A., Zulhmadi, F. \& Harun, A., 2016, 'The benefits and challenges of E-procurement implementation: A case study of Malaysian company', International Journal of Supply Chain Management, 6(1), 329-332.

More, M., 2016, Small businesses to benefit from Central Supplier Database, viewed 26 September 2019, from https://www.sanews.gov.za/south-africa/smallbusinesses-benefit-central-supplier-database.

Mpinganjira, M., 2012, 'Diffusion of e-government services: A citizen's perspective', Journal of Public Administration 47(2), 500-617.

Nawi, M.N.M., Deraman, R., Bamghade, J.A., Zulhumadi, F. \& Riazi, M., 2017, 'E-Procurement in Malaysian construction industry: Benefits and challenges in implementation', International Journal of Supply Chain Management 6(1), 209-213.

PurchaseControl, 2019, The advantages and disadvantages of e-procurement, viewed 07 January 2020, from https://www.purchasecontrol.com/blog/advantages-anddisadvantages-of-e-procurement/

Purchasing \& Procurement Center, 2017, E-procurement trends in the global marketplace, viewed 10 January 2020, from https://www. purchasing-procurementcenter.com/e-procurement-trends.html.

Raymond, J., 2008, 'Benchmarking in public procurement', Benchmarking: An International Journal 15(6), 782-793. https://doi.org/10.1108/146357708109 15940

Rotchanakitumnuai, S., 2013, 'The governance evidence of e-government procurement', Transforming Government: People, Process and Policy 7(3), 309-321. https://doi. org/10.1108/TG-01-2013-0004

StatsSA, 2017, Supplier information leaflet, viewed 26 September 2019, from https:// www.statssa.gov.za/supplier_database/csd/Supplier_Information_Leaflet.pdf.

Stebbins, R.A., 2011, What is exploration? Sage, Thousand Oaks, CA. 
Thomas, A., Abdoulaye, K., Frannie, L. \& Sithabile, M., 2007, Trends in public procurement in Africa: Opportunities and challenges of capacity building interventions, viewed 19 March 2019, from https://siteresources.worldbank.org/ INFORMATIO Africa.pdf.

Tshamaano, V.L., 2012, Impact of the supply chain management on service delivery: The case study of provincial department of Economic Development, Environment and Tourism in the Limpopo Province, University of Limpopo, South Africa, viewed n.d., from: http://ulspace.ul.ac.za/handle/10386/704
Van Weele, A., 2010, Purchasing supply chain management, 5th rev. edn., Cengage Learning, London.

Wins, M., 2017, The benefits of training employees for effective eProcurement practices, viewed 16 April 2019, from https://www.procurement-academy.com/ benefits-training-eprocurement-practices/.

Zitha, H.E., Sebola, M.P. \& Mamabolo, M.A., 2016, 'Compliance to procurement processes, deviant behaviour and effects on service delivery in the public sector', Journal of Public Administration and Development Alternatives 1(1), 59-76. 